УДК 316.4

\title{
СОЦИАЛЬНАЯ БЕЗОПАСНОСТЬ И НОВЫЙ ФОРМАТ ПОСЕЛЕНИЯ
}

\author{
М.В. Жукова, А.В. Гаськов \\ Рубиовский институт (филиал) Алтайского государственного университета, \\ Рубиовск, Россия \\ e-mail.ru:krukova@rb.asu.ru,kinopolus@mail.ru
}

\section{DOI: 10.14258/ssi(2019)4-07}

Анализируются вопросы обеспечения социальной безопасности. Прежде всего отмечено, что социальную безопасность невозможно гарантировать без сохранения систем природы. Рассмотрен вопрос о развитии движения экологических поселений как феномена, направленного на обеспечение экологической безопасности. Авторами проведен пилотажный социологический опрос ( $\mathrm{n}=129)$ среди молодежи по выяснению отношения к жизни в сельской местности и в экологических поселениях.

Ключевые слова: сочиальная безопасность, экологическая безопасность, экологическое поселение.

\section{PUBLIC SAFETY AND NEW FORMAT OF THE SETTLEMENT}

\author{
M. V. Zhukova, A.V. Gaskov \\ Rubtsovsk Institute (branch) of Altai State University, Rubtsovsk, Russia, \\ e-mail.ru:krukova@rb.asu.ru,kinopolus@mail.ru
}

The work is devoted to the study of public safety issues. First of all, it is noted that public safety cannot be guaranteed without the preservation of natural systems. The issue of the development of the movement of ecological settlements as a phenomenon aimed at ensuring environmental safety is considered. The authors conducted a pilot sociological survey $(n=129)$ among young people to clarify the attitude to life in rural areas and ecological settlements.

Keywords: public safety, ecological safety, ecological settlement.

В настоящее время, по мнению многих авторов, социальная безопасность не только приобретает приоритетное значение, но и выявляет необходимость изменения системных подходов к социальной форме развития будущего России, необходимость более динамичного развития гражданского общества, создания устойчивого социального и правового порядка в обществе.

Само понятие «безопасность» как сложнейшее социальное явление объективно имеет конкретно-исторический характер. В самом упрощенном виде безопасность - это отсутствие опасностей, сохранность. Но в реальной жизни смысловое 
значение безопасность приобретает только в связи с конкретными объектами или сферой человеческой деятельности и окружающей среды (Государственная..., 2011).

Рядом авторов безопасность понимается как состояние защищенности жизненно важных интересов объектов безопасности: личности, общества и государства, обеспечиваемое субъектами безопасности, от общественно опасных деяний и иных вредоносных явлений социального, техногенного и природного характера посредством использования системы мер, средств и способов, предусмотренных законом (Кондрашов, 1998; Макаркин, 2014; Серебрянников, 1996). В данной формулировке главными объектами безопасности являются личность, общество и государство.

В целом понятие «безопасность» определяется как состояние защищенности личности, общества и государства от внутренних и внешних угроз.

Основными угрозами социальной безопасности являются угрозы, наносящие ущерб социально-экономическим, духовным, экологическим и прочим интересам общества - как населения страны в целом, так и отдельным его группам, а также социальным образованиям межгосударственного, межнационального характера (Федотова, 2014).

На сегодняшний день состояние социальной безопасности в Российской Федерации характеризуется как нестабильное, несмотря на принимаемые государством и обществом усилия (Концепция..., 2013).

Следует отметить, что устойчивое развитие России, высокое качество жизни и здоровья ее населения и социальную безопасность невозможно гарантировать без сохранения систем природы и поддержания соответствующего качества окружающей среды.

По мнению Т.А. Бочковой и С.А. Мамий, на территории России сложное состояние окружающей среды, становится очевидной экологическая деградация. Поэтому экологическая безопасность приобретает особую актуальность в последние десятилетия. Обеспечение экологической безопасности России - условие жизни государства, предполагающее смену существующих приоритетов на экологические, что невозможно без изменений в сознании людей, системы ценностей общества в целом, понимания сущности проблем экологии и обязательного участия каждого человека в их решении (Бочкова, 2017).

С целью повышения уровня экологической безопасности, в том числе улучшения качества окружающей природной среды, продуктов питания, желания вести здоровый образ жизни, социализации детей в «здоровом» социуме, желания жить «на земле» многие люди переезжают жить в экопоселения (Гоманова, 2017).

Создание экопоселений является способом переоценки современной модели потребления через проявление сознательного снижения материальных потребностей и изменения образа жизни в гармонии с окружающей природной средой. В современной литературе экопоселения рассматриваются как новая форма сельских сообществ (Кулясов, 2008), которая позволяет соотнести перспективы их развития с возможной последующей интеграцией в процесс устойчивого развития сельских территорий Российской Федерации. Также экопоселения рассматриваются как социальная экологическая практика в интересах устойчивого развития общества, ко- 
торая предлагает новую модель альтернативного образа жизни в гармонии с природой и повышением качества жизни за счет создания благоприятных экологических и социальных условий (Рыбакова, 2012, 2014).

Развитие экологических поселений началось в середине 60 -х годов прошлого столетия в западных странах. Вместо жизни в загрязненных населенных пунктах организаторы экопоселений выбирали жизнь в небольших деревнях без вредного воздействия на природу. На протяжении четверти века численность экопоселений во всем мире возрастала, возникла необходимость во взаимодействии и обмене опытом, поэтому в 1991 г. в США была создана Глобальная сеть экопоселений — Global Ecovillage Network (Глибовец, 2016).

В России первые экологические поселения возникли в 1990-е гг. Идее создания собственного экопоселения способствовала ставшая доступной информация о зарубежном опыте. Люди, уставшие от большого количества накопившихся проблем в своей жизни, начали искать способы устойчивого развития. Кроме того, постоянная загородная жизнь и работа на самого себя больше не являлись незаконными. Первым экопоселением России является Гришино, созданное Владиславом Кирбятьевым на востоке Ленинградской области на месте заброшенной деревни. В России экопоселения в большей части находятся в Краснодарском крае, в Крыму, на Алтае, в Подмосковье, на Кавказе, в Поволжье, в Прибайкалье, на Саянах. В 2005 г. открыта Российская сеть экопоселений, включающая практически все существующие на тот момент экологические поселения нашей страны, вступившая в Глобальную сеть экопоселений (Мирзагитова, 2008).

В России экопоселения являются родовыми общинами. На одно родовое поместье отводится площадь один гектар. Родовым поместьем является община, которая состоит из членов семьи. В родовых общинах принято соблюдать старинные обычаи и традиции сел, такие как передача знаний от стариков молодым. Во время создания экопоселения несколько семей могут по согласию объединиться в одно родовое поместье. Делается это, если идея создания поселения была обоюдной, если среди семей есть единомышленники, они строят общие планы на будущее. При условии, что в экопоселение переезжают люди разных профессий, оно становится более жизнеспособным в силу того, что они обладают важными качествами для жизнеобеспечения поселения (учителя, врачи, агрономы, электрики и другие специалисты).

Управление экопоселением осуществляют главы семей, которые составляют совет общины. Внутри поселений нет товарно-денежного оборота, жители осуществляют финансовые расходы только при поездках в города или в соседние деревни. В семьях покупки обсуждаются и планируются заранее. Как правило, между экопоселениями и ближайшими деревнями складываются хорошие отношения для сотрудничества и партнерства с администрацией, школами, клубами и другими социальными учреждениями, частными предпринимателями. С целью получения дополнительного заработка экопоселения принимают туристические группы, организуют концерты народной музыки, а также песен собственного сочинения. Жители поселений занимаются сельским хозяйством, содержат пасеки. Осуществляются 
продажи деревянных и текстильных изделий из натуральных материалов, которые изготавливаются поселенцами. Нередко это становится основным источником доходов жителей экопоселений (Дмитриев, 2014).

На первых стадиях создания экопоселения общине необходимо разработать свои правила на собственность. Имущество поселения не принадлежит одному лицу, оно распределяется между семьями. Общины приобретают или арендуют землю у государства на собственные средства, поэтому, прежде чем принять решение о его организации, необходимо тщательно обдумать все детали. Организаторы поселения осуществляют достаточно трудоемкий процесс, связанный с созданием нового населенного пункта (Лазутин, 2009).

С целью изучения отношения к экологическим поселениям было проведено пилотажное социологическое исследование методом количественного сбора данных при использовании стандартизированной анкеты.

В выборочном обследовании приняли участие студенты $(\mathrm{n}=129)$ среднего профессионального образования Рубцовского института (филиала) АлтГУ в возрасте 15-18 лет.

Проведенное исследование позволяет сделать предположение о том, что в большинстве случаев молодежь в возрасте 15-18 лет не хочет жить в сельской местности (63,3\% студентов, обучающихся по специальностям среднего профессионального образования на базе 9 классов; 58,0\% студентов, обучающихся по специальностям среднего профессионального образования на базе 11 классов). Только $20,0 \%$ (на базе 9 классов) и 18,8\% (на базе 11 классов) ответили, что хотят жить сельской местности.

Большинству респондентов знакомо, что такое экологическое поселение, это $56,7 \%$ студентов, обучающихся по специальностям среднего профессионального образования на базе 9 классов, и 55,1\% - на базе 11 классов, а 20,0\% (на базе 9 классов) и $18,8 \%$ (на базе 11 классов) - хорошо представляют, что такое экологическое поселение. Есть студенты — 5,0\% (на базе 9 классов) и 14,5\% (на базе 11 классов), которые хотели бы сами жить в таком поселении.

Студенты считают, что в России нужно развивать натуральное хозяйство, так как это способствует здоровому образу жизни (38,3\% - на базе 9 классов; 27,5\% на базе 11 классов), удовлетворению потребностей в пище, еде и жилье на более выгодных условиях (26,7\% — на базе 9 классов; 43,5\% — на базе 11 классов) и в силу того, что экологическая ситуация критична $(30,4 \%$ - на базе 11 классов, 20,0\% на базе 9 классов).

На вопрос, нужно ли создавать новые деревни, респонденты ответили, что нужно, так как в них ведется экологичный и здоровый образ жизни (36,7\% студентов, обучающихся по специальностям среднего профессионального образования на базе 9 классов и 23,2\% студентов, обучающихся по специальностям среднего профессионального образования на базе 11 классов), это возможность обрести независимость от урбанистической инфраструктуры жизнеобеспечения $(18,8 \%$ - на базе 11 классов, 8,3\% - на базе 9 классов), это будет содействовать возрождению России $(8,7 \%$ — на базе 11 классов и 5,0\% — на базе 9 классов $) ; 20,0 \%$ - на базе 11 классов 
и $15,9 \%$ - на базе 9 классов затруднились с ответом, а 30,4\% — на базе 11 классов и $31,7 \%$ - на базе 9 классов дали отрицательный ответ.

Респонденты считают, что необходимо возрождать славянскую культуру, так как это наше наследие (20\% — на базе 9 классов и 18,8\% - на базе 11 классов), способствует созданию справедливого общества (11,7\% - на базе 9 классов; 7,2\% - на базе 11 классов), является возможностью реализации духовных потребностей - в духовной эволюции, сотворчестве, счастье $(6,7 \%$ - на базе 9 классов; $15,9 \%$ - на базе 11 классов), это возрождение осознанного и здорового образа жизни (11,6\% - на базе 11 классов). Однако 38,3\% (на базе 9 классов) и 33,3\% (на базе 11 классов) опрошенных дают отрицательный ответ.

При обработке эмпирических данных были отобраны значимые высказывания относительно предложенных утверждений в зависимости от статуса респондентов (учащаяся молодежь или работающая молодежь). Анализ значимых высказываний был проведен с использованием SPSS 20.0 методом мультиномиальной логистической регрессии. С целью оценки достоверности меры связи между переменными и анализа значимых высказываний использовались статистические инструменты: критерий хи-квадрат $(\chi 2)$, уровень значимости (p) и коэффициент детерминации (R2). Рассмотрим результаты анализа.

1.Респонденты, обучающиеся по специальностям среднего профессионального образования на базе 9 классов, считают, что развитие натурального хозяйства способствует здоровому образу жизни (юноши - 30795769,2 (95\% CI 4824658,659935-196569222,801678), девушки - 1,0; $\mathrm{p}=0,000)$, является решением проблемы критичности экологической ситуации (юноши - 27374017,1 (95\% CI 3450269,622227-217182102,950890), девушки - 1,0; p =0,000), а также способствует удовлетворению потребностей в пище, еде и жилье на более выгодных условиях (юноши — 20530512,8 (95\% CI 2891999,839892-145747572,700567), девушки - 1,0; $\mathrm{p}=0,000)$.

Среди юношей, обучающихся по специальностям среднего профессионального образования, было отмечено, что развитие натурального хозяйства является решением проблемы критичности экологической ситуации (юноши (9 классов) 66779168,5 (95\% CI 8781399,639170-507829906,418509), юноши (11 классов) — 1,0; $\mathrm{p}=0,000)$, способствует удовлетворению потребностей в пище, еде и жилье на более выгодных условиях (юноши (9 классов) — 28619643,6 (95\% СI 3902944,088554$209863115,067750)$, юноши (11 классов) - 1,0; p = 0,000), а также способствует здоровому образу жизни (юноши (9 классов) — 11924851,5 (95\% CI 1503029,50814194610307,595388), юноши (11 классов) - 1,0; $\mathrm{p}=0,000)$.

Следует отметить, что у многих респондентов вызвал затруднение ответ на вопрос о необходимости развития натурального хозяйства (юноши - 102652564,1 (95\% CI 102652564,132248-102652564,132248), девушки - 1,0; p = 0,000) и (юноши (9 классов) - 42929465,5 (95\% CI 42929465,519685-42929465,519685), юноши (11 классов) - 1,0; $=0,000)$.

2. Юноши, обучающиеся по специальностям среднего профессионального образования на базе 11 классов, на вопрос «Знакомо ли вам, что такое экологическое поселение?» 
дают статистически значимый ответ: «Да, знакомо и хотел бы сам жить в таком поселении» (юноши - 13,3 (95\% CI 1,068545-166,373641), девушки - 1,0; p = 0,044).

\section{Выводы}

1.В большинстве случаев молодежь в возрасте 15-18 лет не желает проживать в сельской местности.

2.Респондентам знаком такой вид поселений, как экопоселения. Некоторые из опрошенных высказали мнение, что хотели бы жить в таких поселениях. Причем статистически значимые результаты были получены относительно ответов юношей, обучающихся по специальностям среднего профессионального образования на базе 11 классов.

3. Юноши придерживаются мнения, что в России нужно развивать натуральное хозяйство, в силу таких причин как:

• улучшение экологической ситуации;

- удовлетворение потребностей в пище, еде и жилье на более выгодных условиях;

- возможность ведения здорового образа жизни.

4. Студентами высказывается мнение о необходимости создания новых деревень, так как это даст возможность:

• вести экологичный и здоровый образ жизни;

- обрести независимость от урбанистической инфраструктуры жизнеобеспечения;

- возродить Россию.

5. Молодежь задумывается о необходимости возрождения славянской культуры, так как она является нашим наследием и будет способствовать развитию справедливого общества, реализации духовных потребностей и возрождению осознанного и здорового образа жизни.

В заключение отметим, что главная задача современного общества и государства - предоставить всем гражданам возможности самореализации, когда критерием развития становится качество жизни человека — то, что он делает в действительности и что может сделать, получая новые возможности.

Экопоселения, с нашей точки зрения, являются попыткой поиска нового образа жизни и новой формы населенных пунктов, в которых формируется дружественная социальная среда единомышленников; реализуется потребность в самореализации, свобода творчества, здоровый образ жизни, желание жить «на земле»; происходит улучшение качества окружающей природной среды, продуктов питания, социализация детей в «здоровом» социуме, т.е. повышается уровень экологической безопасности. Все это имеет принципиальное значение для социального развития и обеспечения социальной безопасности Российской Федерации.

\section{БИБЛИОГРАФИЧЕСКИЙ СПИСОК}

Бочкова Т.А., Мамий С.А. Проблемы экологической безопасности России. Научный журнал КубГАУ, 2017, No. 125. URL: https://cyberleninka.ru/article/n/problemyekologicheskoy-bezopasnosti-rossii-1. 
Глибовец В.Л. Феномен экологических поселений. Псковский регионологический журнал, 2016. URL: https://cyberleninka.ru/article/n/fenomen-ekologicheskih-poseleniy.

Гоманова С.О. Экопоселения России: институциональный аспект. Власть, 2017, o. 1.

Государственная и муниципальная социальная политика. Курс лекций: учебное пособие / под ред. Н.А. Волгина. М. : КНОРУС, 2011.

Дмитриев Ю.А., Карпов А.Е. Социально-экономическое развитие сельских территорий посредством формирования и развития поселений родовых поместий. Региональная экономика: теория и практика, 2014, № 13.

Кондрашов Б.П. Общественная безопасность и административно-правовые средства ее обеспечения: дис. ... д-ра юрид. наук. М., 1998.

Концепция общественной безопасности в Российской Федерации (утв. Президентом РФ 14.11.2013 № Пр-2685). URL: https://www.consultant.ru/document/cons_doc_ LAW 154602/.

Кулясов И.П., Кулясова А.А. Экопоселения - новая форма сельских сообществ в России. Экология и жизнь, 2008, No. 10, 20-26.

Лазутин Ф. Этапы юридического оформления экопоселения «Ковчег» как населенного пункта. Ковчег. URL: http://www.eco-kovcheg.ru/think8.html.

Макаркин С.В. Безопасность: понятие, основные принципы, правовая основа ее обеспечения. Техносферная безопасность, 2014, №. 2, 51-55.

Мирзагитова Л. Экопоселения России - 2008. ECOLOGY.md. URL: http:/ecology. $\mathrm{md} /$ page/ekoposelenija-rossii.

Рыбакова М.В., Щукина М.Ю. Экономический потенциал экопоселений в устойчивом развитии сельских территорий. Финансы: Теория и Практика, 2014, No. 3.

Рыбакова М. В., Щукина М. Ю. Экопоселения как социальная экологическая практика общества. Социально-гуманитарные знания, 2012, No. 4, 316-324.

Серебрянников В., Хлопьев А. Социальная безопасность России. М.: ИСПИ РАН, 1996.

Федотова Ю.Г. Понятие общественной безопасности Российской Федерации. Российская юстиция, 2014, No. 11, 2-5.

\section{REFERENCES}

Bochkova, T.A., Mamij, S.A. (2017). Problemy ekologicheskoj bezopasnosti Rossii [Problems of ecological safety of Russia]. Scientific journal of Kubsau, no 125. Available at: https://cyberleninka.ru/article/n/problemy-ekologicheskoy-bezopasnosti-rossii-1.

Glibovets, V.L. (2016). Fenomen ekologicheskikh poselenij [Phenomenon of ecological settlements]. Pskov regionological journal. Available at: https://cyberleninka.ru/article/n/ fenomen-ekologicheskih-poseleniy.

Gomanova, S.O. (2017). Ekoposeleniya Rossii: institutcional'nyj aspect [Ecovillages of Russia: institutional aspect]. Power, No. 1. Available at: https://cyberleninka.ru/article/n/ ekoposeleniya-rossii-institutsionalnyy-aspekt. 
Volgina, N.A. (Ed.). (2011). Gosudarstvennaya i municipal'naya sotcial'naya politika. Kurs lekcij: uchebnoe posobie [State and municipal social policy. A course of lectures: textbook]. Moscow: KNORUS.

Dmitriev, Yu.A., Karpov, A.E. (2014). Social'no-ekonomicheskoe razvitie sel'skih territorij posredstvom formirovaniya i razvitiya poselenij rodovyh pomestij [Social and economic development of rural territories by forming and developing patrimony settlements]. Regional economy: theory and practice, no 13, 2-8.

Kondrashov, B.P. (1998). Obshchestvennaya bezopasnost' $i$ administrativno-pravovye sredstva ee obespecheniya [Public security and administrative and legal means of its ensuring] (PhD Thesis). Moscow.

Koncepciya obshchestvennoj bezopasnosti v Rossijskoj Federacii (utv. Prezidentom RF 14.11.2013 № Pr-2685) (2013) [The concept of public security in the Russian Federation (Utv. President of the Russian Federation 14.11.2013 N Pr-2685)]. URL: https://www. consultant.ru/document/cons_doc_LAW_154602/.

Kulyasov, I.P., Kulyasova, A.A. (2008). Ekoposeleniya - novaya forma sel'skih soobshestv v Rossii [Ecovillages as a new form of rural communities in Russia]. Ecology and life, no 10, 20-26.

Lazutin, F. (2009). Etapy yuridicheskogo oformleniya ekoposeleniya «Kovcheg» kak naselennogo punkta [Stages of legal registration of eco-settlement "Ark" as a settlement]. Available at: http://www.eco-kovcheg.ru/think8.html.

Makarkin, S.V. (2014). Bezopasnost': ponyatie, osnovnye principy, pravovaya osnova ee obespecheniya [Safety: the concept, the main principles, the legal basis for its provision]. Technosphere safety. Scientific journal, vol. 3, no 2, 51-55.

Mirzagitova L. Ekoposeleniya Rossii - 2008 [Ecovillages of Russia - 2008]. ECOLOGY.md. Available at: http://ecology.md/page/ekoposelenija-rossii.

Rybakova, M.V., Shchukina, M.Yu. (2014). Ekonomicheskij potencial ekoposelenij v ustojchivom razvitii sel'skih territorij [Economic potential of ecovillages in sustainable development of rural territories]. Finance: Theory and Practice, no 3. URL: https://cyberleninka.ru/article/n/ekonomicheskiy-potentsial-ekoposeleniy-v-ustoychivom-razvitii-selskih-territoriy.

Rybakova M.V., Shchukina M.Yu. (2012). Ekoposeleniya kak sotcial'naya ekologicheskaya praktika obshchestva [Ecovillage as a social ecological practice of society]. Social and humanitarian knowledge, no 4, 316-324.

Serebryannikov, V., Flakes, A. (1996). Sotcialnaya bezopasnost'Rossii [Social security of Russia]. Moscow: ISPR of the RAS.

Fedotova, Yu.G. (2014). Ponyatie obshchestvennoj bezopasnosti Rossiiskoj Federacii [The notion of public security of the Russian Federation]. Russian justice, no 11, 2-5. 